\title{
Research Paper: Clarifying the Roles of Hardiness and Hopelessness in Relation to Suicidal Ideation Among Malaysian Undergraduate Students
}

\author{
Abbas Abdollahi ${ }^{*}$, Simin Hosseinian ${ }^{1}$, Rogheih Nooripour ${ }^{1}$, Mahmoud Najafi $^{2}$ \\ 1. Department of Counseling, Faculty of Educational Sciences and Psychology, Alzahra University, Tehran, Iran \\ 2. Department of Psychology, Faculty of Psychology \& Educational Sciences, Semnan University, Semnan, Iran.
}

\begin{tabular}{|c|c|}
\hline $\begin{array}{l}\text { Use your device to scan } \\
\text { and read the article online }\end{array}$ & Hosseinian S Noorimour $\mathrm{R}$ \\
\hline 口ifin: & $\begin{array}{l}\text { ness in Relation to Suicidal Ideation Among Malaysian Undergraduate Students. Journal of Practice in Clinical Psychology, 5(4), } \\
\text { 243-250. https://doi.org/10.29252/NIRP.JPCP.5.4.243 }\end{array}$ \\
\hline 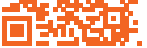 & dof: https://doi.org/10.29252/NIRP.JPCP.5.4.243 \\
\hline
\end{tabular}

Article info:

Received: 14 Apr. 2017

Accepted: 08 Aug. 2017
Keywords:

Hopelessness, Hardiness, Suicidal ideation

\section{ABSTRACT}

Objective: Committing suicide is a growing issue across the globe, and it is essential to know the insights of the etiology of suicide. Therefore, we conducted this study to clarify the roles of hardiness and hopelessness in relation to suicidal ideation.

Methods: This was a cross-sectional study. Study participants consisted of 500 (230 males and 270 females) Malaysian undergraduate students from two public universities during the fall semester 2014. All the respondents completed the Personal Views Survey, Beck Hopelessness Scale, and the Beck Scale for Suicidal Ideation.

Results: Structural equation modeling indicated that undergraduate students with high level of hopelessness and low level of hardiness were more likely to report suicidal ideation. Hopelessness partially mediated the relationship between hardiness and suicidal ideation. Furthermore, hardiness moderated the relationship between hopelessness and suicidal ideation.

Conclusion: These findings have enhanced the existing literature by clarifying the roles of hopelessness and hardiness in relation to suicidal ideation among undergraduate students.

\section{Introduction}

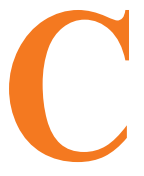

ommitting suicide is a serious problem worldwide, and it is the third highest cause of deaths among adolescents aged between 17 and 24 years (Centers for Disease Control and Prevention, 2013; Malaysian Psychiatric Association, 2007). According to a 2008 report released by the Institute for Public Health (IPH), the prevalence of acute and chronic suicidal ide- ation in young Malaysians aged between 17 and 24 years was found to be $10.0 \%$ and $26.0 \%$, respectively, which is higher than that of people in other age groups (Institute for Public Health (IPH), 2008). Garlow et al. (2008) reported that suicidal ideation has shown an increasing trend among university students, indicating that university students constituted an at-risk population.

Due to the fact that the state of Selangor has the highest rate of suicide than that of other states (Hayati \&

* Corresponding Author:

Abbas Abdollahi, PhD

Address: Department of Counseling and Advising, Faculty of Educational Sciences and Psychology, Alzahra University, Tehran, Iran.

Tel: +98 (911) 8187318

E-mail: abdollahi.abbas58@gmail.com 
Kamarul, 2008), in this study, we recruited adolescents aged between 17 and 24 years (undergraduate students in universities located in Selangor) as respondents. We believe that it is essential to identify early signs of suicidal ideation and formulate effective strategies to prevent it. Therefore, in this study, we focused on understanding suicidal ideation and its associated variables among the undergraduate students in Malaysia.

Feeling of hopelessness in adolescents has been regarded as one of the factors leading to suicide and suicidal ideation (Lai Kwok \& Shek, 2010). Indeed, there is a significant correlation between hopelessness and suicidal ideation (Handley et al., 2013; Miranda, Valderrama, Tsypes, Gadol, \& Gallagher, 2013; Lai Kwok \& Shek, 2010). It is postulated that individuals with a high feeling of hopelessness attribute negative events to internal, stable, and global factors, which may contribute to suicidal ideation and lead to suicide (Abdollahi et al., 2016). In addition, the diathesis-stress hopelessness theory (Kobasa, Maddi, \& Kahn, 1982) states that some individuals are unable to cope with stress. Therefore, they feel hopeless, and this negative feeling may lead to a suicidal act.

The construct of hardiness which is crucial for the understanding of suicidality has been recently reported (Abdollahi et al., 2016). The psychological hardiness is the ability of an individual to feel committed and motivated when he/she encounters challenges in their lives (Kobasa, Maddi, \& Kahn, 1982; Maddi et al., 2002). According to Kobasa's definition, two mechanisms have been proposed to explain hardiness: high-hardy individuals are able to 1 . Behave in an adaptive manner whenever they experience stress (Maddi, Harvey, Khoshaba, Fazel, \& Resurreccion, 2009); and 2. Appraise hopeless and stressful condition as a new challenge which is controllable (Abdollahi, Talib, Yaacob, \& Ismail, 2015).

By searching Google Scholar, PubMed, Science Direct, and Psycho Info websites for articles published from 2000 to 2017, no author has employed hardiness as a moderating role in suicidal ideation research. Till date, the majority of the studies have focused on hardiness on stress management (Phillips, 2011; Vidrine et al., 2011). Therefore, in this study, we aimed to apply the hardiness theory on suicidal ideation among undergraduate students. Previous studies have witnessed the value of hardiness in human health apart from suicidal ideation (Jameson, 2014). Hardy persons are usually committed and are able to formulate solutions to new problems/challenges. They view challenges as opportunities; hence, they can handle stressful life events better and possess better physical and mental health (Phillips, 2011).
The hardiness theory (Kobasa et al., 1982) presents two types of appraisals in relation to suicidality. The first appraisal must be performed whenever there is a threatening and uncontrollable situation (the likelihood of suicidal ideation increases). The second appraisal involves the relationship between hopelessness and suicidal ideation, where the positive assessment of event may prevent suicidality. In addition, Garrosa et al. (2008) concluded that individuals with strong hardiness have the courage, motivation, and strategies to turn stressful circumstances into growth opportunities. According to our knowledge, studies detailing with suicidal ideation and hardiness are rather limited. Therefore, we intended to clarify the role of hardiness as a moderator between hopelessness and suicidal ideation among undergraduate students.

In addition, to the best of our knowledge, there are no studies regarding the effect of hopelessness as a mediator between hardiness and suicidal ideation among Malaysian undergraduate students. Therefore, in this study, we aim to understand the mediating role of hopelessness between hardiness and suicidal ideation among undergraduate students. We examined numerous hypotheses between variables and suicidal ideation. First, a negative relationship can be observed between hardiness (including components such as commitment, control, and challenge) and suicidal ideation. Second, there is a positive relationship between hopelessness and suicidal ideation. Third, hardiness can moderate the relation between hopelessness and suicidal ideation among undergraduate students. Finally, hopelessness can mediate the relation between hardiness (including components such as commitment, control, and challenge) and suicidal ideation.

\section{Methods}

In this study, 500 undergraduate students (230 males and 270 females) from two public universities in Malaysia participated. Their mean age was 20.28 years (range $=18$ to 24 years, standard deviation $(\mathrm{SD})=2.58$ ). Among the students, there were 223 Malay students, 124 Chinese students, 113 Indian students, and 14 students from other ethnicities. In terms of marital status, 382 students were single, 113 students were married, and 5 students were separated or widowed. Of the 500 participants, 150 students were freshmen, 115 students were sophomores, 125 students were juniors, and 110 students were seniors. In terms of religion, 224 participants were Muslims, 131 participants were Hindus, 106 participants were Buddhists, 15 participants were Taoists, and 4 participants were from other religious affiliations. 
We employed the multistage cluster sampling method. Based on the three main fields of study, that is, science, social science, and technical, a faculty was randomly chosen from each field. Four classes from the chosen faculty were then randomly selected. The questionnaires were distributed to the chosen students (576 questionnaires), and 500 usable questionnaires were obtained. Only 36 students refused to complete the questionnaires, and 40 participants were classified as outliers and their questionnaires were excluded from the analyses.

This study was approved by the ethics committee of University Putra Malaysia (UPM/TNCPI/1.418.1). Written consents were obtained from the participants: they were informed that their participations were voluntary and anonymous, and they could withdraw from the study anytime.

The Personal Views Survey (Maddi et al., 2006) consists of 18 worded items that were used to measure the three components of hardiness: commitment, control, and challenge. A 4-point Likert scale was employed: 0: Not at all true; 1: Somewhat true; 2: True; and 3: Very true. An acceptable internal consistency $(\alpha)$ has been reported earlier (Maddi et al., 2006): 0.70-0.75 for commitment, $0.61-0.84$ for control, $0.60-0.71$ for challenge, and $0.80-0.88$ for total hardiness. Based on this scale, in this study, the values of convergent validity (average variance extracted), construct reliability (CR), and Cronbach's alpha for commitment component were 0.63 , 0.73 , and 0.72 , respectively. The values of average variance extracted, CR, and Cronbach's alpha were respectively $0.59,0.71$, and 0.71 for control and $0.53,0.74$, and 0.73 for challenge components.

The Beck Hopelessness Scale (BHS) (Beck, Weissman, Lester, \& Trexler, 1974) consists of 20 items that were used to assess hopelessness (from the true/false answers). BHS scale indicated good reliability with $\alpha=0.93$, and a strong internal consistency with KR-20 coefficients ranging from 0.83 to 0.93 was revealed (Beck et al., 1974). Based on this scale, in this study, the convergent validity (average variance extracted), CR, and Cronbach's alpha for hopelessness component was found to be $0.60,0.75$, and 0.74 , respectively.

The Beck Scale for Suicidal Ideation (Beck, Steer, \& Ranieri, 1988) is a self-report with 21 items. This scale was used to assess suicidal ideation, planning, and intent to commit suicide via a 3 -point Likert scale $(0,1,2)$. In order to enhance the reliability of observed indicators, factor analyses were performed by using item parcels for suicidal ideation. We noticed that three factors had eigenvalues of $\geq 1.0$. Therefore, suicidal ideation with three factors was studied. Previous researchers (Bryan, Ray Sannerud, Morrow, \& Etienne, 2013; Polanco Roman \& Miranda, 2013) have reported that the internal consistency and the convergent validity of BSSI were acceptable. Based on this scale, in this study, the convergent validity (average variance extracted), CR, and Cronbach's alpha for suicidal ideation component were found to be $0.69,0.81$, and 0.80 , respectively.

There were $0.81 \%-1.81 \%$ of missing items. In order to resolve this issue, a list-wise deletion method available in AMOS 20 software was applied. The data were distributed normally: skewness ranged from -1.77 to 1.68 and kurtosis ranged from -2.61 to 2.11 for all variables. According to Byrne (2010), if skewness and kurtosis are between -2 to +2 and -7 to +7 , respectively, one can assume multivariate normality of the data. In addition, this model showed good fit indices: $\mathrm{CMIN} / \mathrm{df}=2.95, \mathrm{P}<0.01$, $\mathrm{CFI}=0.953, \mathrm{GFI}=0.903, \mathrm{TLI}=0.940, \mathrm{RMSEA}=0.063$.

\section{Results}

\section{Descriptive statistics}

Table 1 reports the inter-correlations between hopelessness, suicidal ideation, commitment, control, and challenge for male and female students. In addition, the SDs, the actual range, and the mean values are shown.

\section{Structural model}

As shown in Figure 1, commitment, control, challenge, and hopelessness components showed a strong correlation with suicidal ideation. While commitment, control, and challenge were found to be negatively correlated with suicidal ideation, a positive correlation existed between hopelessness and suicidal ideation.

\section{Mediation test of hopelessness}

The model treated commitment, control, and challenge as exogenous variables. However, both hopelessness and suicidal ideation were modeled as endogenous variables. The normal theory method (Baron \& Kenny, 1986) was employed for testing the mediation effects. In order to introduce a mediation effect in the model, it must be proven that a full mediation model is superior to an indirect model (Baron \& Kenny, 1986). The goodness-of-fit for full mediation model and indirect model could be analyzed based on nested model comparisons (Kline, 2010).

From the nested model comparisons, the full mediation model exhibited the following features: $\chi^{2}=2.958$. 
Table 1. Correlation between study variables for male and female students, and the mean, SD and actual range

\begin{tabular}{|c|c|c|c|c|c|}
\hline Variables & 1 & 2 & 3 & 4 & 5 \\
\hline Hopelessness & 1 & $0.633^{* * *}\left(0.854^{* * *}\right)$ & $-0.283^{* *}\left(-0.217^{* *}\right)$ & $-0.300^{*}\left(-0.150^{*}\right)$ & $-0.259^{*}\left(-0.129^{*}\right)$ \\
\hline $\mathrm{SI}$ & & 1 & $-0.788^{* *}\left(-0.488^{* *}\right)$ & $-0.252^{*}\left(-0.488^{* *}\right)$ & $-0.359^{* *}\left(-0.215^{*}\right)$ \\
\hline Commitment & & & 1 & $0.720^{* * *}\left(0.667^{* * *}\right)$ & $0.669^{* * *}\left(0.601^{* * *}\right)$ \\
\hline Control & & & & 1 & $0.664^{* * *}\left(0.517^{* * *}\right)$ \\
\hline Challenge & & & & & 1 \\
\hline Mean & 11.21 & 88.15 & 13.78 & 12.56 & 12.8 \\
\hline SD & 3.53 & 15.28 & 7.28 & 5.63 & 6.58 \\
\hline Actual range & $3-16$ & $15-153$ & $4-18$ & $4-17$ & $6-17$ \\
\hline
\end{tabular}

Results for male are presented first, and results for female are presented in a parenthesis.

$\mathrm{P}>0.01, \mathrm{GFI}=0.904, \mathrm{CFI}=0.953$, TLI $=0.940$, and $\mathrm{RM}$ $\mathrm{SEA}=0.063$; and the indirect model exhibited the following features: $\chi^{2}=3.274, \mathrm{P}>0.01, \mathrm{GFI}=0.914, \mathrm{CFI}=0.944$, TLI $=0.930$, and RMSEA $=0.068$. The date could be fitted by both models. However, the full mediation model gave better fitting because it showed smaller Akaike Information Correction (AIC) of 743.560 (AIC of indirect model was found to be 810.689) and larger Parsimony Normed Fit Index (PNFI) of 0.740 (PNFI of indirect model was 0.736).
From the abovementioned method, hopelessness mediates the relationships between commitment, control, and challenge with suicidal ideation. The results, as demonstrated in Table 2, show that the relationships between suicidal ideation and variables such as commitment, control, and challenge in the direct model were significant $(\beta=-0.511,-0.383$, and -0.447 , respectively). In addition, as deduced from the mediation model, the relationships between hopelessness and variables such as commitment, control, challenge, and hopelessness were

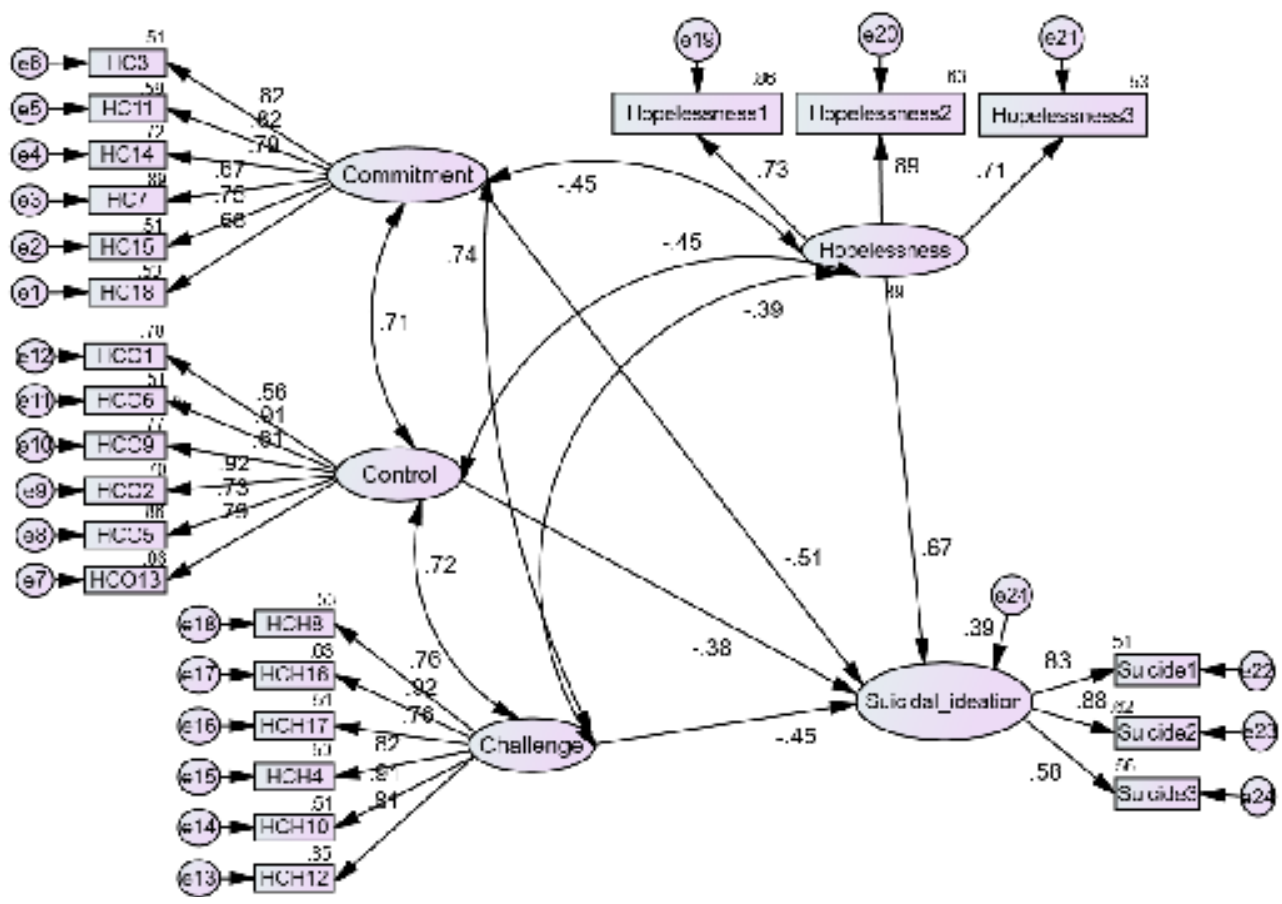

Figure 1. Structural model of suicidal ideation; All pathways were significant with $\mathrm{P}<0.01$ 
Table 2. Standard regression weight in the full mediation, direct, and indirect model

\begin{tabular}{|c|c|c|c|c|c|}
\hline DV & & IV & Mediation Model & Direct Model & Indirect Model \\
\hline Hopelessness & $<--$ & Commitment & $-0.385^{* *}$ & & $-0.886^{* *}$ \\
\hline Hopelessness & $<--$ & Control & $-0.483^{* *}$ & & $-0.204^{*}$ \\
\hline Hopelessness & $<--$ & Challenge & $-0.245^{* *}$ & & $-0.257^{*}$ \\
\hline Suicidal ideation & $<--$ & Hopelessness & $0.661^{* * *}$ & & $0.72^{* * *}$ \\
\hline Suicidal ideation & $<--$ & Commitment & $-0.412^{* *}$ & $-0.511^{* *}$ & \\
\hline Suicidal ideation & $<--$ & Control & $-0.211^{*}$ & $-0.383^{* *}$ & \\
\hline Suicidal ideation & $<--$ & Challenge & $-0.196^{*}$ & $-0.447^{* *}$ & \\
\hline
\end{tabular}

significant ( $\beta=-0.886,-0.204$, and 0.257 , respectively). Meanwhile, the relationship between hopelessness and suicidal ideation was significant as well $(\beta=0.723)$. Although the standard regressions for the direct relationships between suicidal ideation and variables such as commitment, control, and challenge decreased when hopelessness was added as a mediator variable in the mediation model, the relationship was still significant. Therefore, the partial mediation of hopelessness on the relationships between commitment, control, challenge, and suicidal ideation was supported.

\section{Moderation test of hardiness}

By comparing the unconstrained model and the measurement residual model, the unconstrained model $\left(\chi^{2}=1.884, \mathrm{P}<0.01, \quad \mathrm{RMSEA}=0.042, \quad \mathrm{CFI}=0.993\right.$, $\mathrm{GFI}=0.988, \mathrm{NFI}=0.985)$ and the measurement residuals model $\left(\chi^{2}=3.409, \mathrm{P}<0.01\right.$, $\mathrm{RMSEA}=0.070, \mathrm{CF}=0.952$, $\mathrm{GFI}=0.950, \mathrm{NFI}=0.930)$ were significant. However, the unconstrained model is better than the measurement residuals model because its chi-square value is smaller (Davis, 2008; Hair, Black, Babin, Anderson, \& Tatham, 2010). The findings show that the effect of hardiness (based on mean value of 26.01) is significant.

The results reveal that there is a significant relationship between hopelessness and suicidal ideation for low hardy students $(\beta=0.751, \mathrm{P}<0.01)$, while the path hypothesis for high hardy students is not significant $(\beta=0.452$, $\mathrm{P}<0.58$ ). Therefore, the moderating effect of hardiness on the path relationship between hopelessness and suicidal ideation is supported, indicating that low hardy students score higher than that of high hardy students in terms of hopelessness.

\section{Discussion}

In this study, we have demonstrated that hopelessness, commitment, control, and challenge are significantly correlated with suicidal ideation. Hopelessness, commitment, control, and challenge contributed to variance in suicidal ideation (39\%) among undergraduate students. The empirical findings indicated that hopelessness played a mediating role between suicidal ideation and variables such as commitment, control, and challenge. In other words, hardy individuals were less likely to exhibit suicidal ideation even when they experienced intense hopelessness. By finding a relationship between hardiness, hopelessness, and suicidal ideation among the undergraduate students, our results have confirmed the results of previous studies (Abdollahi et al., 2015; Abdollahi et al., 2016). Following this, we have proposed three improvements.

First, the present findings have implied that hardiness may serve as a resilience factor for undergraduate students with suicidal ideation (Erbes et al., 2011). Hopelessness has been regarded as one of the psychological risk factors for suicidal ideation (Johnson et al., 2010; Polanco Roman \& Miranda, 2013). We argue that the existing prediction mechanisms of suicidality, as well as intervention and prevention programs, are not comprehensive. From this study, we find that hardiness could act as a buffering factor and promote predictive validity when it is used to study suicidal ideation. Furthermore, 
individuals who are at risk of suicide can be identified, and hence the risk of suicidal thinking can be reduced.

Second, this study has studied the interaction between hardiness and hopelessness. Previously, the relationship between hardiness and stressful life events was analyzed in a normal population (McVicar, 2003). However, this study has focused on hopelessness instead. We have observed that hardiness could counter hopelessness. Therefore, the concept of hardiness is not restricted to stressful life events, and it could serve as a significant buffering factor for hopelessness and suicidal ideation.

Third, this study has supported the hardiness theory (Maddi \& Khoshaba, 1994), whereby we have found that self-appraisal plays a vital role in the cognitive architecture of suicidality. The findings have shown that hardiness could render positivity and reduce hopelessness and suicidal ideation among Malaysian undergraduate students. It means that undergraduate students with high levels of hardiness are more likely to apply hardy attitudes and courage to confront with suicidal ideation, and they are more flexible in facing problems. Hardy individuals also consider stressful circumstances as being more challenging and controllable and less threatening. Therefore, this study suggests that hardiness plays an important role against suicidal ideation.

\section{Implications for practice}

There are two significant implications for intervention and prevention programs. First, when assessing the risk of suicide of an individual, it is important to account for the presence of hardiness in addition to other risk factors such as hopelessness. Previous studies treated hardiness as a pattern of attitude and skill that could facilitate resilience under stressful circumstances and transform challenges into opportunities (Maddi et al., 2009). Our results show preliminary evidence that in case of undergraduate students hopelessness is not a sole factor that plays a role in suicidal ideation. We believe that hardiness plays a buffer role in the relationship between hopelessness and suicidal ideation. Second, although causality cannot be determined, it is possible that hardiness training may alter the effect of suicidal ideation and may decrease the level of hopelessness.

Decreasing the suicidal ideation in an individual is the primary goal of any clinical intervention. Hardiness training procedure has been used in previous studies (Maddi et al., 2002; Maddi et al., 2009; Maddi, Harvey, Khoshaba, Fazel, \& Resurreccion, 2011), for example, narratives on hardiness, inspirational examples, exer- cises, and periodic checkpoints. The primary aim in this case is exercising and developing the hardy skills of coping, social support, and self-care, as well as using the feedbacks obtained through these efforts to deepen the hardy attitudes of commitment, control, and challenge.

In this study, the participants consisted of Malaysian undergraduate students. The primary objective of this study was the identification of hopelessness as a mediator between hardiness and suicidal ideation. According to the results, hardiness could decrease the negative feelings of hopelessness and suicidal ideation. However, our results were generated based on self-report questionnaires. Although the methods employed in this study were psychometrically adequate, a multi-method approach would enhance its validity. It has been proven that participants may overlap the perceptions of mental health with well-being when they are requested to complete questionnaires about mental health and hardiness simultaneously. Clinical interviews should be conducted to resolve this issue.

In conclusion, results of this study have shown that hardiness could decrease the detrimental influence of hopelessness in the development of suicidal ideation among Malaysian undergraduate students.

\section{Acknowledgments}

Authors would like to thank all those participants who have kindly collaborated in this project. The authors received no financial support for research, authorship, and/ or publication of this article.

\section{Conflict of Interest}

All authors certify that this manuscript has neither been published in whole nor in part nor being considered for publication elsewhere. The authors have no conflicts of interest to declare.

\section{References}

Abdollahi, A., Abu Talib, M., Carlbring, P., Harvey, R., Yaacob, S. N., \& Ismail, Z. (2016). Problem solving skills and perceived stress among undergraduate students: The moderating role of hardiness. Journal of Health Psychology, 135910531665326. doi: $10.1177 / 1359105316653265$

Abdollahi, A., Abu Talib, M., Yaacob, S. N., \& Ismail, Z. (2014). The role of hardiness in decreasing stress and suicidal idea- 
tion in a sample of undergraduate students. Journal of Humanistic Psychology, 55(2), 202-22. doi: 10.1177/0022167814543952

Abdollahi, A., Talib, M. A., Yaacob, S. N., \& Ismail, Z. (2015). Problem solving skills and suicidal ideation among Malaysian college students: The mediating role of hopelessness. Academic Psychiatry, 40(2), 261-7. doi: 10.1007/s40596-015-0383-0

Baron, R. M., \& Kenny, D. A. (1986). The moderator mediator variable distinction in social psychological research: Conceptual, strategic, and statistical considerations. Journal of Personality and Social Psychology, 51(6), 1173-82. doi: 10.1037/00223514.51.6.1173

Beck, A. T., Steer, R. A., \& Ranieri, W. F. (1988). Scale for suicide ideation: Psychometric properties of a self report version. Journal of Clinical Psychology, 44(4), 499505. doi: 10.1002/1097-4679(198807)44:4<499::aidjclp2270440404>3.0.co;2-6

Beck, A. T., Weissman, A., Lester, D., \& Trexler, L. (1974). The measurement of pessimism: The Hopelessness Scale. Journal of Consulting and Clinical Psychology, 42(6), 861-5. doi: 10.1037/ h0037562

Bryan, C. J., Ray Sannerud, B., Morrow, C. E., \& Etienne, N. (2013). Guilt is more strongly associated with suicidal ideation among military personnel with direct combat exposure. Journal of Affective Disorders, 148(1), 37-41. doi: 10.1016/j. jad.2012.11.044

Byrne, B. M. (2010). Structural equation modeling with AMOS: Basic concepts, applications, and programming. Abingdon: Routledge Academic.

Centers for Disease Control and Prevention. (2013). Key injury and violence data. Retrieved from https://www.cdc.gov/injury/wisqars/overview/key_data.html

Davis, J. W. (2008). Handbook of univariate and multivariate data analysis and interpretation with SPSS. The American Statistician, 62(3), 268. doi: 10.1198/000313008x332287

Erbes, C. R., Arbisi, P. A., Kehle, S. M., Ferrier Auerbach, A. G., Barry, R. A., \& Polusny, M. A. (2011). The distinctiveness of hardiness, positive emotionality, and negative emotionality in National Guard soldiers. Journal of Research in Personality, 45(5), 508-12. doi: 10.1016/j.jrp.2011.07.001

Garlow, S. J., Rosenberg, J., Moore, J. D., Haas, A. P., Koestner, B., Hendin, H., et al. (2008). Depression, desperation, and suicidal ideation in college students: results from the American foundation for suicide prevention college screening project at Emory University. Depression and Anxiety, 25(6), 482-8. doi: 10.1002/da.20321

Hair, J. F., Black, W. C., Babin, B. J., Anderson, R. E., \& Tatham, R. L. (2010). Multivariate data analysis: A global perspective. London: Pearson.

Handley, T. E., Kay Lambkin, F. J., Baker, A. L., Lewin, T. J., Kelly, B. J., Inder, K. J., et al. (2013). Incidental treatment effects of CBT on suicidal ideation and hopelessness. Journal of affective disorders, 151(1), 275-83. doi: 10.1016/j.jad.2013.06.005

Hayati, A. N., Kamarul A. K. (2008). National suicide registry Malaysia. Medical Journal of Malaysia, 63(Suppl), 50-4. PMID: 19227674
Institute for Public Health (IPH). (2008). The Third Health and Morbidity Survey (NHMSIII) 2006, vol. 1. Putrajaya: Ministry of Health.

Jameson, P. R. (2014). The effects of a hardiness educational intervention on hardiness and perceived stress of junior baccalaureate nursing students. Nurse Education Today, 34(4), 603-7. doi: 10.1016/j.nedt.2013.06.019

Johnson, J., Gooding, P. A., Wood, A. M., Taylor, P. J., Pratt, D., \& Tarrier, N. (2010). Resilience to suicidal ideation in psychosis: Positive self appraisals buffer the impact of hopelessness. Behaviour Research and Therapy, 48(9), 883-9. doi: 10.1016/j. brat.2010.05.013

Kline, R. B. (2010). Principles and practice of structural equation modeling. New York: Guilford publications.

Kobasa, S. C., Maddi, S. R., \& Kahn, S. (1982). Hardiness and health: A prospective study. Journal of Personality and Social Psychology, 42(1), 168-77. doi: 10.1037/0022-3514.42.1.168

Lai Kwok, S. Y. C., \& Shek, D. T. L. (2009). Personal and family correlates of suicidal ideation among chinese adolescents in Hong Kong. Social Indicators Research, 95(3), 407-19. doi: 10.1007/s11205-009-9528-4

Lai Kwok, S. Y. C., \& Shek, D. T. L. (2010). Hopelessness, parentadolescent communication, and suicidal ideation among Chinese adolescents in Hong Kong. Suicide and Life Threatening Behavior, 40(3), 224-33. doi: 10.1521/suli.2010.40.3.224

Maddi, S. R., \& Khoshaba, D. M. (1994). Hardiness and mental health. Journal of personality Assessment, 63(2), 265-74. doi: 10.1207/s15327752jpa6302_6

Maddi, S. R., Harvey, R. H., Khoshaba, D. M., Fazel, M., \& Resurreccion, N. (2009). Hardiness training facilitates performance in college. The Journal of Positive Psychology, 4(6), 566-77. doi: $10.1080 / 17439760903157133$

Maddi, S. R., Harvey, R. H., Khoshaba, D. M., Fazel, M., \& Resurreccion, N. (2011). The relationship of hardiness and some other relevant variables to college performance. Journal of Humanistic Psychology, 52(2), 190-205. doi: $10.1177 / 0022167811422497$

Maddi, S. R., Harvey, R. H., Khoshaba, D. M., Lu, J. L., Persico, M., \& Brow, M. (2006). The personality construct of hardiness, III: Relationships with repression, innovativeness, authoritarianism, and performance. Journal of personality, 74(2), 575-98. doi: 10.1111/j.1467-6494.2006.00385.x

Maddi, S. R., Khoshaba, D. M., Jensen, K., Carter, E., Lu, J. L., \& Harvey, R. H. (2002). Hardiness training for high-risk undergraduates. NACADA Journal, 22(1), 45-55. doi: 10.12930/02719517-22.1.45

Malaysian Psychiatric Association. (2007). Suicide - It's an SOS [Internet]. Retrieved from http://www.psychiatry-malaysia. org/article.php?aid=504

McVicar, A. (2003). Workplace stress in nursing: A literature review. Journal of Advanced Nursing, 44(6), 633-42. doi 10.1046/j.0309-2402.2003.02853.x

Miranda, R., Valderrama, J., Tsypes, A., Gadol, E., \& Gallagher, M. (2013). Cognitive inflexibility and suicidal ideation: Mediating role of brooding and hopelessness. Psychiatry Research 210(1), 174-81. doi: 10.1016/j.psychres.2013.02.033 
Phillips, J. (2011). Hardiness as a defense against compassion fatigue and burnout. Journal of Emergency Nursing, 37(2), 125. doi: 10.1016/j.jen.2010.10.012

Polanco Roman, L., \& Miranda, R. (2013). Culturally related stress, hopelessness, and vulnerability to depressive symptoms and suicidal ideation in emerging adulthood. Behavior therapy, 44(1), 75-87. doi: 10.1016/j.beth.2012.07.002

Vidrine, J. I., Reitzel, L. R., Figueroa, P. Y., Velasquez, M. M., Mazas, C. A., Cinciripini, P. M., et al. (2013). Motivation and problem solving (MAPS): Motivationally based skills training for treating substance use. Cognitive and Behavioral Practice, 20(4), 501-16. doi: 10.1016/j.cbpra.2011.11.001 